\title{
ANALYSIS OF RESILIENT DESIGN BY THERMOACOUSTIC ADAPTATION OF TROPICAL URBAN MODEL
}

\author{
FX Teddy Badai SAMODRA \\ Institut Teknologi Sepuluh Nopember, Surabaya, Indonesia \\ E-mail:fxteddybs@arch.its.ac.id
}

Received 02 September 2017; accepted 04 December 2017

\begin{abstract}
Climate and urban environment changes lead to tropical building adaptation and resilient strategy. They focus especially on thermal comfort and noise propagation variation as the result of global warming and urban growth. This study analyzes a conceptual design of tropical urban model on integrated design of thermal and acoustic (thermoacoustic) issues. By experimental measurement and simulation method using Computational Fluid Dynamics, the findings are directed to meet the standards and to recommend the new guidelines for sustainable urban building. The research location is in Surabaya as the urban tropical lowland area and EcoHouse of ITS, a tropical building model in an urban environment, was built as experiment model. The results highlighted that the noise barrier should consider 5.24\% of the maximum window to wall ratio (WWR) in tree dimensionally analysis, horizontally and vertically. Providing vertical ventilation is the best solution for urban density, but the orientation and its flanking noise affect the passive cooling. In general, there are some factors having a high contribution in addition to WWR, such as wind acceleration, the distance, and building material.
\end{abstract}

Keywords: noise control, resilient design, thermal comfort, thermoacoustic, tropical climate, urban environment.

\section{Introduction}

In an urban area, regarding the climate change issues, the tropical building and its occupants adapt to the critical context from the comfortable environment to the disadvantaged one. That situation could lead the resilient strategy. The manifestations of a resilient architecture should have its own physical characteristics by change over time (Laboy, Fannon 2016). The adapted urban buildings exist in dynamic relationships among technology, human use, and the surrounding natural environment (Anderies 2014). A stronger driver should be a role for the built environment in natural processes, resilience, and robustness. Therefore, the standard of the urban environment determines the different factors for the built environment such as thermal, indoor air quality, aural and visual environment comfort (Huang et al. 2012). The wind could be a generator for both physiological cooling for restoring thermal comfort and environmental noise propagation. Hence, the tropical problems of heat and noise are considered the most important contributors to the indoor environmental quality.
In general, the thermoacoustic discusses devices development for thermal and acoustical control related to power generation, refrigeration, and the other similar majors. However, this study offers thermoacoustic as conceptual design of tropical urban model on integrated design of thermal and acoustics issues consisting of thermal performance and urban community noise control. It focuses especially on thermal comfort and noise propagation variation as the result of global warming and urban growth. It has relationships with the climate conditions as one factor in affecting the architecture and city planning, simultaneous with urban topography (Zonouz 2015). However, there were no specific previous findings related the requirements for integrated factors, especially for the tropical building. Most of them analyzed many factors separately (Kruger, Zannin 2007; Huang et al. 2012; Caniato et al. 2017) or effect one factor to the others only (Hodgson, Khaleghia 2012; Freihoefer et al. 2015; Paris-Newton et al. 2016).

In relationships with the urban design, tropical building adaptation and resilient strategy are led by climate and urban environment changes. It needs further 
analysis of dealing thermal with noise problem as the most critical environmental factors. The objective of this study is to analyze the conceptual design of tropical urban model on the combined design of thermal and acoustics issues. Therefore, the integrated analysis and findings are conducted in this study, such as the vertical and horizontal ventilation and noise propagation analysis and recommended Window to Wall Ratio (WWR) for controlling both thermal and acoustical problems.

\section{Research methods}

The research location is in Surabaya as the urban tropical lowland area and Eco-House of ITS (Institut Teknologi Sepuluh Nopember campus), a tropical building model in the urban environment, was built as experiment model and case study. The location and the object of the study were determined with consideration of the existence of a tropical building that became an eco-friendly residential model. As shown in Figure 1, the research location is in the campus area of ITS Surabaya with identification profile as follows:

Architect: Professor Silas (ITS), Indonesia;

Dr Y. Kodama, Kobe Design University (Japan);

Owner: Ministry of Construction, Indonesia;

Infrastructure Development Institute of Japan;

Location: Surabaya, Indonesia; $7^{\circ} \mathrm{N}, 112^{\circ} \mathrm{E}$, Lowland

Altitude (3 m);

Climate: Hot, Humid;

Area: $294 \mathrm{~m}^{2}$.

(source: Roaf et al. 2007)

The weather station, environment meter, and sound recorder are set to evaluate the field condition in the real time for a week in every orientation of outdoor and all levels of the indoor environment (Fig. 2 and Fig. 3).
Furthermore, by experimental and simulation method using Computational Fluid Dynamics (CFD) software simulation, the results of the research are directed to meet the international, World Health Organization (WHO), and national (Indonesian National Standard, SNI) standards. The study also contributes to recommend new guidelines for sustainable urban design.

\section{Discussion}

\section{Thermal and acoustical standard}

An adaptive thermal comfort in the tropical urban area has changed the way of looking at thermal comfort in naturally ventilated buildings. However, the buildings have remained essentially the same for the last 20 years and pose some concerns (Vellei et al. 2017). It significantly extends the current natural adaptive comfort boundary. In the year-on-year weather variability, it is depended greatly on the location (Coley et al. 2017).

According to the international standard (WHO 1990), thermal comfort recommendation for warm climates is on the range of mean comfort neutrality temperatures in the tropics, resulting from combined autonomic and behavioral temperature regulation in different world climates. The acceptable and safe range of thermal comfort neutrality is $17^{\circ} \mathrm{C}$ to $31^{\circ} \mathrm{C}$. As part of the thermal performance, the acceptable indoor air quality in living area as the main justification for ventilation suggested by ANSI/ASHRAE Standard 62.1-2004 should be a minimum of 0.35 air changes per hour but not less than $15 \mathrm{CFM}(7.5 \mathrm{~L} / \mathrm{s})$ per person. The building ventilation is normally obtained by openings of infiltration and natural ventilation. However, for calculating the air changes per hour, the volume of

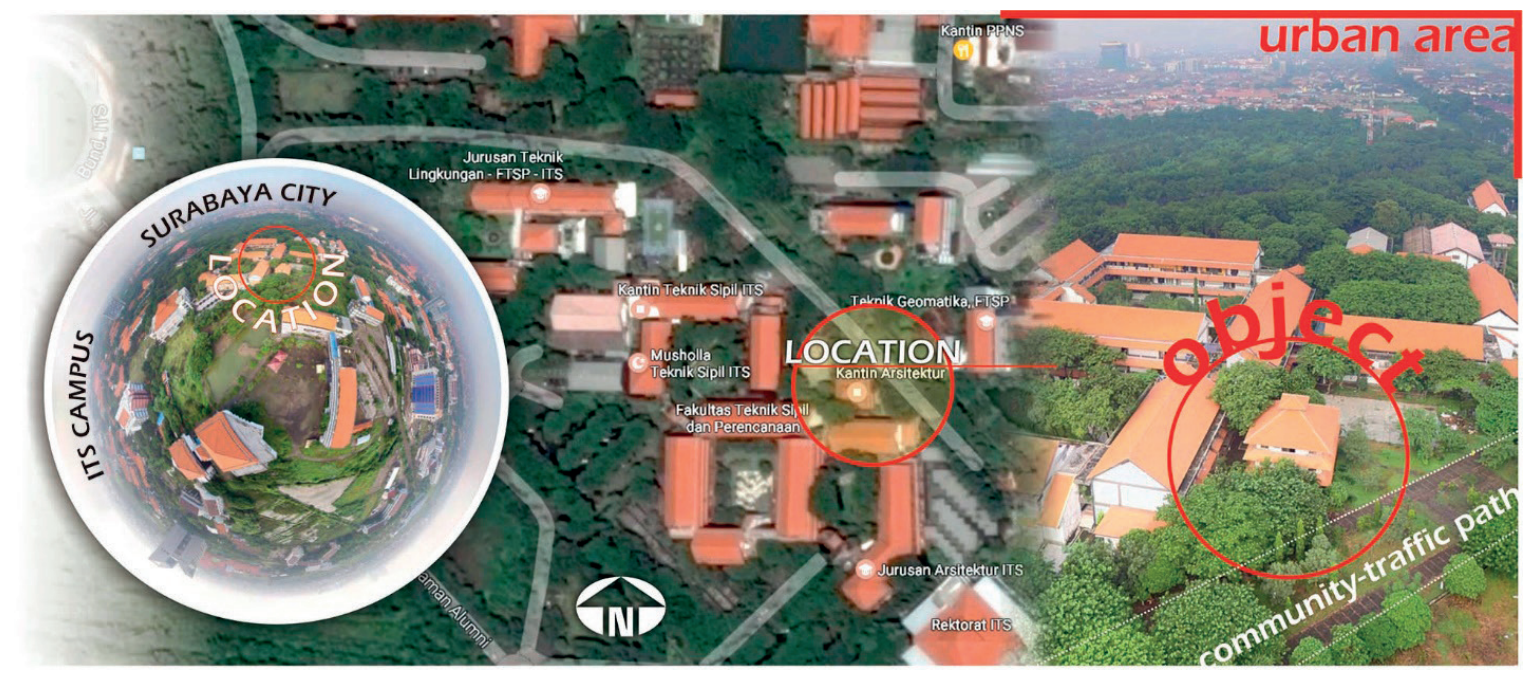

Fig. 1. Research location

Source: https://www.360cities.net and author's illustration, August 2017. 

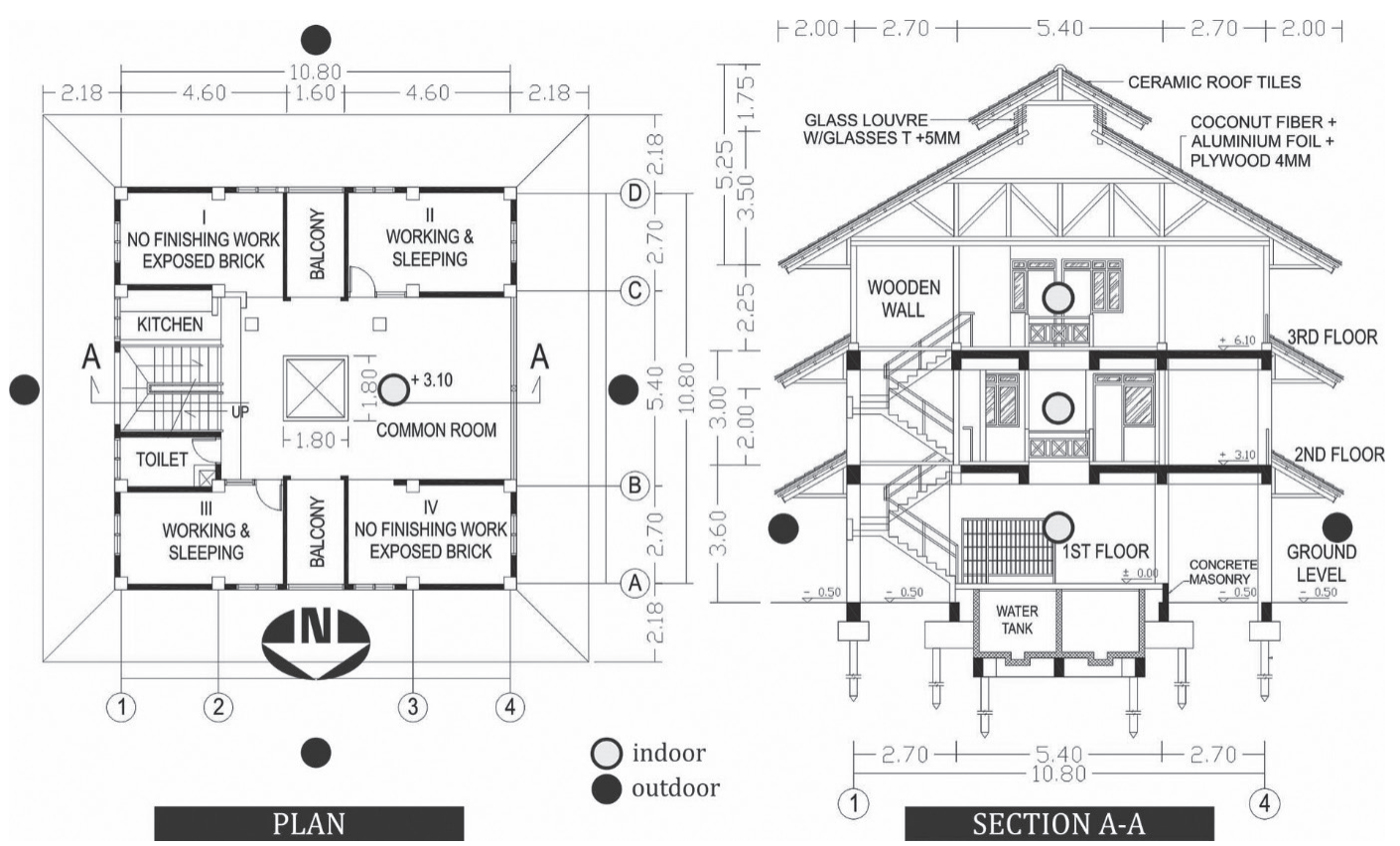

Fig. 2. Building profile and measurement setting point Source: Author's illustration, February 2017.

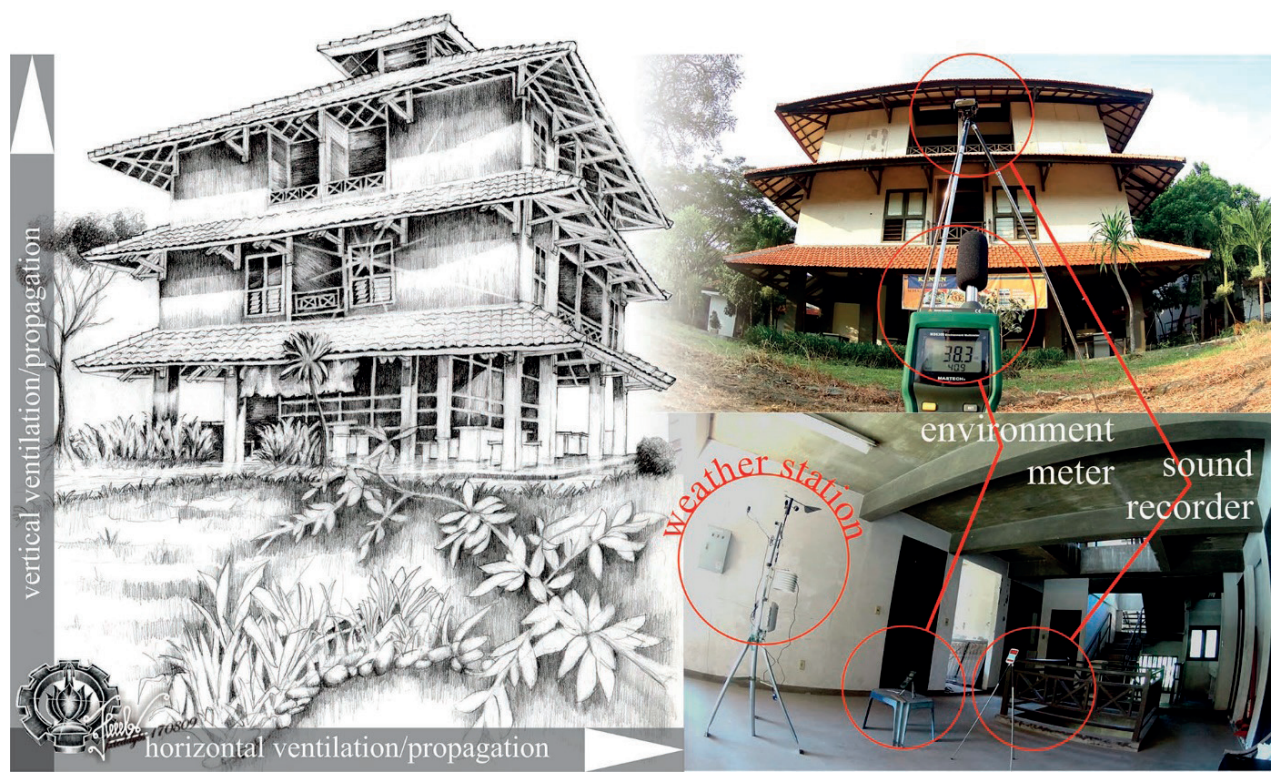

Fig. 3. Measurement method and instruments

Source: Author's sketch and photograph, May-August 2017.

all areas of the indoor environment is considered and calculated within the conditioned space.

Different from building thermal control, there is no significant variation of climate in noise control for an urban building. It is likely depended on the noise source for every urban condition in the countries. Thus, WHO (Berglund et al. 2000) provided the guide for community noise in specific environments. For the living environment, the outdoor condition for highest annoyance during the daytime and the evening is
$55 \mathrm{~dB}$. It is higher than the moderate level of $50 \mathrm{~dB}$. In the other hand, the tolerance for sleep disturbance on the night-time for the indoor area is $30 \mathrm{~dB}$ while the indoor environment is $35 \mathrm{~dB}$ during the daytime and evening in general. These are as a guideline for critical health effect, speech intelligibility and with moderate annoyance during the daytime and the evening. In fact, noise disturbance has increased hugely in the last 15-20 years (Caniato et al. 2016). Even if traffic noise is generally considered as the first cause of disturbance, 
both for annoyance or sleep problems, in many cases the source is related to community noise such as music, people speaking or external noisy machinery.

In Indonesian building regulation, Indonesian National Standard (SNI) has taken an important role to guide the standard for thermal control of a building. The newest SNI for Energy Conservation for Air Conditioning System in Building (2011) released that thermal comfort criteria for lowland region as a location of research in a maximum of Dry-Bulb Temperature (DBT) is $24-27^{\circ} \mathrm{C}$ or $25.5^{\circ} \mathrm{C} \pm 1.5^{\circ} \mathrm{C}$ with Relative Humidity (RH) is $60 \pm 5 \%$ (Monthly DBT condition: $34^{\circ} \mathrm{C}$ or $28^{\circ} \mathrm{C}$ of DBT in average). In 1996, The Minister for the Environmental Decree of Indonesia issued Noise Level Standard. Noise Level Limits for Housing and Human Settlement is $55 \mathrm{dBA}$ (specific criteria and weighted for environmental noise), which is no specific information for indoor or outdoor or for daytime or night-time.

\section{Building and environment performances}

Compared to the past condition (Kodama et al. 1999), the conducted field measurement in current time shows that similar fluctuation of indoor environment results $2-3{ }^{\circ} \mathrm{C}$ increased temperature (see Fig. 4). The resilient concept has been designed for anticipating environmental change such as climate and building density by providing promoted air into building horizontally and vertically. For thermoacoustic, integrated thermal and acoustical condition, this tropical urban model experiences weakness in controlling both heat and noise problem. As shown in
Figure 5, in all location and condition for Indonesia standard, this building could reach the limitation criteria of thermal requirement. In many conditions (location and time), it gets lower than $55 \mathrm{~dB}$ as noise limits recommended by the Minister for the Environmental Decree of Indonesia. In contrast, for international standard as recommended by WHO, the building could reach only in half of the temperature and could not reach better sound pressure level. This indicates that the performance improvement and the general key-point for solving both thermal and acoustical problems are ventilation by accelerating the sufficient and expected wind through building element both outdoor and indoor.

This section also evaluates wind speed requirement condition for dealing physiological cooling of thermal comfort with its control for noise reduction. Before discussing wind effect on noise, the first step is directed to analyze minimum wind speed (air velocity) for physiological cooling (Aynsley, Spruill 1990). Adjustments to the comfort zones for specific local conditions are:

- Decrease comfortable dry-bulb temperatures by $0.8^{\circ} \mathrm{C}$ for each $10 \%$ increase in relative humidity (RH) above $60 \%$;

- Decrease comfortable dry-bulb temperatures by $0.55^{\circ} \mathrm{C}$ for each $2.8^{\circ} \mathrm{C}$ that the mean of surface temperatures of nearby radiating surfaces (mean radiant temperature, MRT) exceeds $38^{\circ} \mathrm{C}$; and

- Increase comfortable dry-bulb temperatures by $0.55^{\circ} \mathrm{C}$ for each $0.15 \mathrm{~m} / \mathrm{s}$ of air velocity for dry-bulb temperatures below $37^{\circ} \mathrm{C}$.

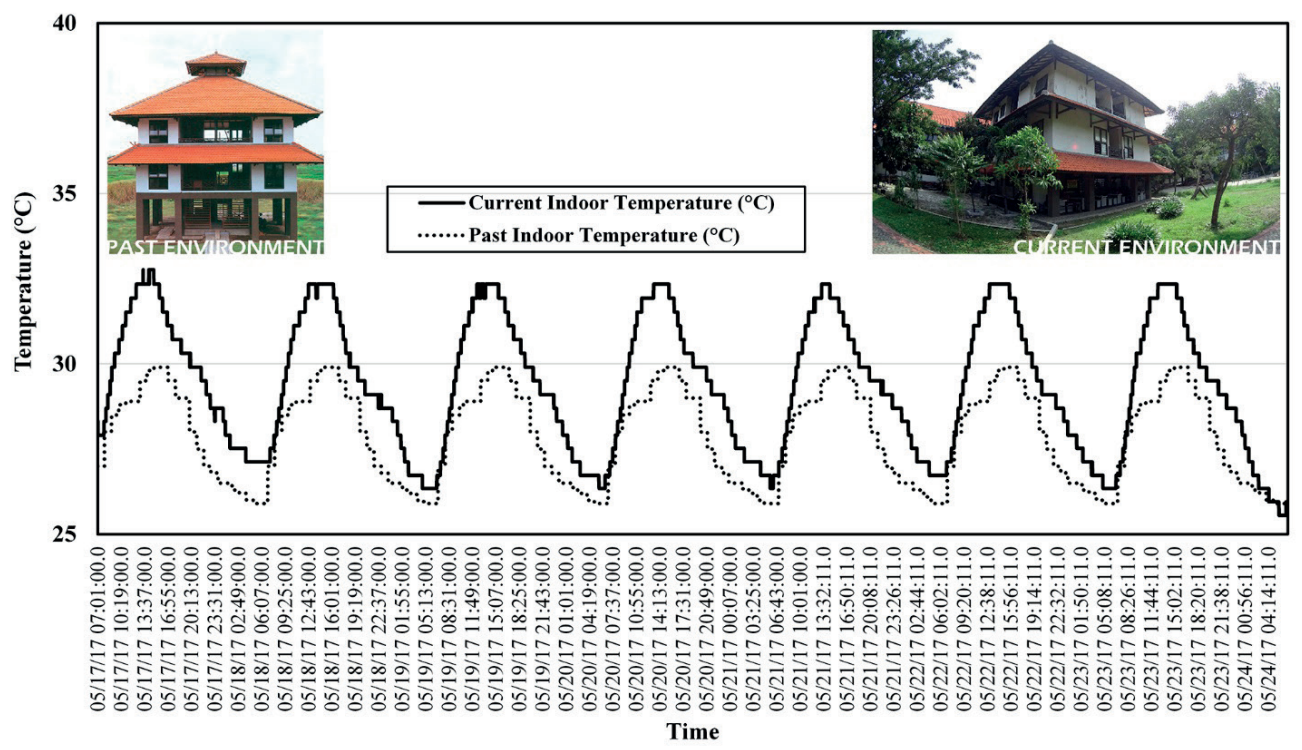

Fig. 4. Measurement result

Source: Kodama et al. 1999, Roaf et al. 2007, author's field measurement, illustration and photograph, May-August 2017. 


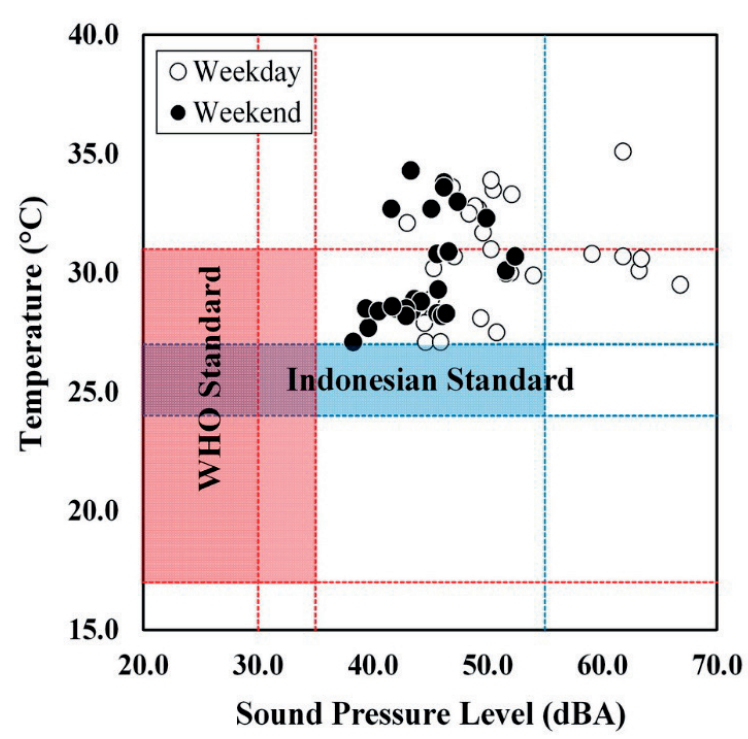

Fig. 5. Thermal and acoustical analysis

Source: Author's field measurement and illustration, July 2017.

These criteria can be used to estimate the air velocity needed to restore thermal comfort, $V_{c}$, at latitude locations less than 30 degrees in warm humid climates by using Equation (1) and the result could be seen in Figure 6.

$$
\begin{aligned}
& \mathrm{V}_{\mathrm{c}}=0.15\left(\mathrm{DBT}-\mathrm{UCT}+\left(\frac{0.8(\mathrm{RH}-60)}{10}\right)+\right. \\
& \left.\left(\frac{0.55(\mathrm{MRT}-38)}{2.8}\right)\right),
\end{aligned}
$$

where: $\mathrm{V}_{\mathrm{c}}-$ Wind speed requirement for physiological cooling [m/s]; DBT - Dry-Bulb Temperature $\left[{ }^{\circ} \mathrm{C}\right]$; UCT - Upper Dry-bulb Temperature $\left[{ }^{\circ} \mathrm{C}\right]$;
RH - Relative Humidity [\%]; MRT - Mean Radiant Temperature $\left[{ }^{\circ} \mathrm{C}\right]$.

In lowland daytime, the urban building has a problem of lower wind speed for restoring thermal comfort (83.3\% is insufficient wind speed) with average minimum $1.5 \mathrm{~m} / \mathrm{s}$ wind speed requirement. Meanwhile, in night-time conditions, buildings do not need the wind for physiological cooling because of its lower air temperature and MRT than daytime. As the second step, Figure 7 shows the vector wind and it relationships on noise. The vector wind, $U_{v e c}$, is the vector component of the average wind speed $U[\mathrm{~m} / \mathrm{s}]$ for the angle $\theta$ between the wind direction and a line perpendicular to the noise source through the prediction point (Equation (2)). $U_{\text {vec }}$ is positive in the downwind direction and negative in the upwind direction. In fact, for short distance of noise to the receiver, the wind has a little effect. The regression value is 0.6 , it means that vector wind has no strong effect on $8 \mathrm{~m}$ distance in this study. It is also indicated by zero of vector wind still has high sound pressure level. However, the value of negative and zero direction of the wind is lower than positive direction. Different from Sakamoto (2015), it indicates an effect of the wind on noise propagation even though in a slightly way. In line with Tanaka, Shiraishi (2008), noise levels are from $10 \mathrm{~dB}$ higher than when it is small and its fluctuations become small.

$$
\mathrm{U}_{\mathrm{vec}}=\mathrm{U}_{\cos } \theta \text {, }
$$

where: $U_{\text {vec }}=U_{\cos } \theta$ - the vector component; $U$ - the average wind speed $[\mathrm{m} / \mathrm{s}] ; \theta$ - the angle between the wind direction and a line perpendicular to the source through a receiver.

For analysis of dealing thermal with noise environment, $\mathrm{U}_{\mathrm{vec}}$ is 1 and the wind direction is $0^{\circ}$. It is used

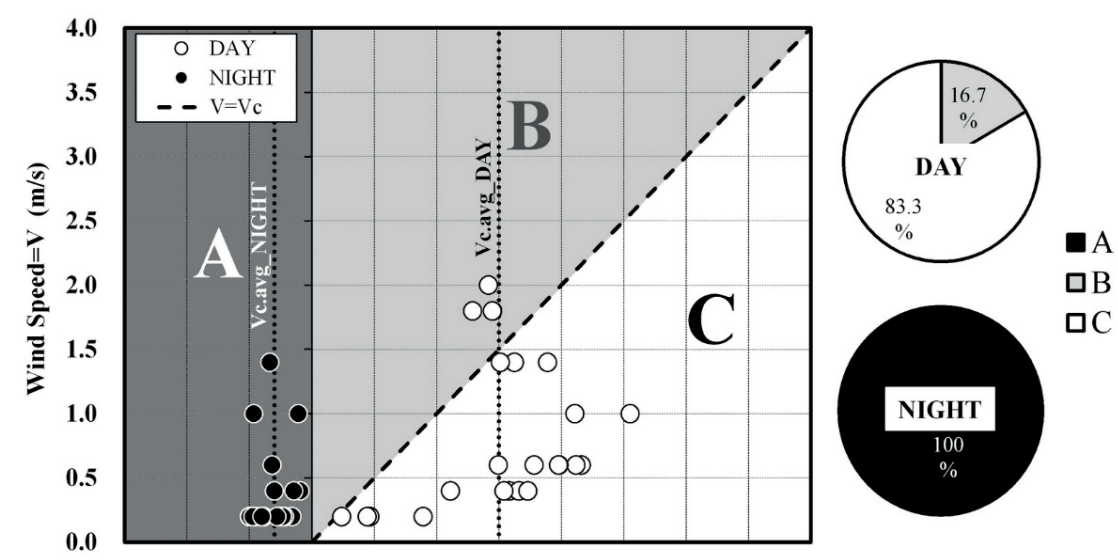

Note: A: no need wind for physiological cooling; B: sufficient wind speed; C: insufficient wind speed Day:06:00-18:00, Night:18:00-06:00.

Fig. 6. Indoor wind speed condition

Source: Author's illustration, July 2017. 


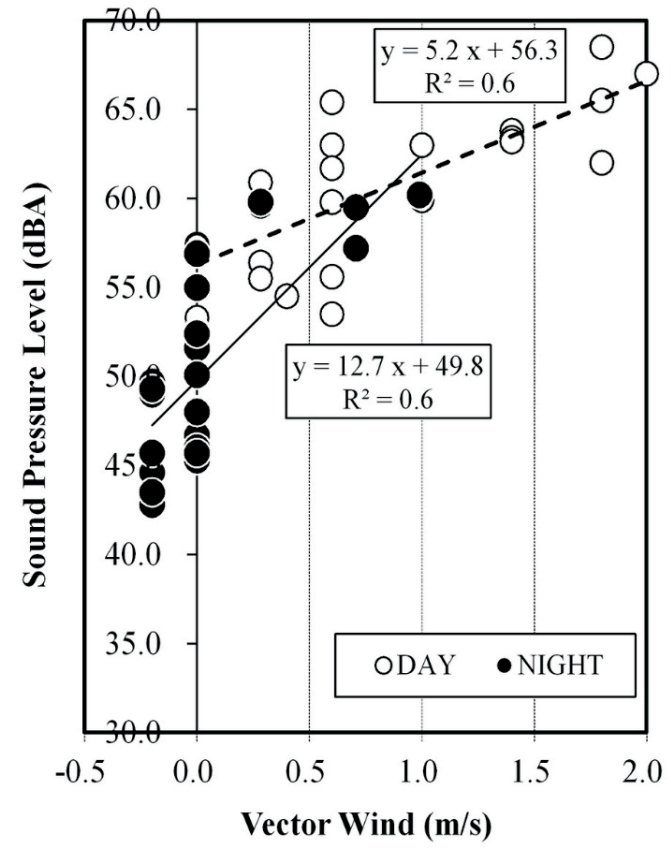

Note: Day: 06:00-18:00, Night: 18:00-06:00; measured from 8 $\mathrm{m}$ of distance source to receiver.

Fig. 7. Vector wind and its effect on noise Source: Author's field measurement and illustration, July 2017.

as critical wind direction, perpendicular to building from noise source (Table 1). By using Equation (3), LAeq $32.5 \mathrm{~m}$ and LAeq $38.5 \mathrm{~m}$ are determined as sound pressure level by the minimum distance $(32.5 \mathrm{~m}$ for daytime, $38.5 \mathrm{~m}$ for night-time) for lowland with maximum wind speed on noise, based on WHO Standard and minimum wind speed for restoring thermal comfort. In $32.5 \mathrm{~m}$ of distance, $1.5 \mathrm{~m} / \mathrm{s} \mathrm{should} \mathrm{be} \mathrm{the} \mathrm{perfect}$ wind speed for restoring thermal comfort and noise control when in $38.5 \mathrm{~m} / \mathrm{s}$, the minimum could be $0 \mathrm{~m} / \mathrm{s}$ for night-time (no need wind speed for thermal comfort), but the maximum wind speed should be $1.5 \mathrm{~m} / \mathrm{s}$ for noise control.

$$
\Delta \text { Lm,line }= \begin{cases}0.88 \log \left(\frac{1}{15}\right) \cdot \mathrm{Uvec}_{\mathrm{ve}} & 1>15 \\ 0 & 1 \leq 15\end{cases}
$$

where: $\Delta \mathrm{L}_{\mathrm{m}, \text { line }}=\mathrm{SPL}-$ Sound Pressure Level $[\mathrm{dB}] ; 1-$ the horizontal distance from the source to the receiver [m].

In the average existing distance from the noise source to receiver $(8 \mathrm{~m})$ and in all locations and time, the condition based on WHO noise limits need minimum distance for noise control. Therefore, it is not recommended for existing distance $(8 \mathrm{~m})$ for lowland building, especially during the daytime because it needs wind speed for thermal comfort.
Table 1. Summary for wind speed requirement for restoring thermal comfort and controlling noise for various distance samples

\begin{tabular}{|c|c|c|c|}
\hline \multirow[b]{2}{*}{$\begin{array}{l}\text { Location/ } \\
\text { Time }\end{array}$} & \multirow[b]{2}{*}{$\begin{array}{c}\text { Distance } \\
\text { Samples } \\
\text { (m) }\end{array}$} & \multicolumn{2}{|c|}{ Wind speed requirement } \\
\hline & & $\begin{array}{l}\text { Average } \\
\text { condition } \\
(\mathrm{m} / \mathrm{s})\end{array}$ & $\begin{array}{l}\text { Hottest time } \\
\text { condition } \\
(\mathrm{m} / \mathrm{s})\end{array}$ \\
\hline \multirow{6}{*}{$\begin{array}{l}\text { Lowland/ } \\
\text { Daytime }\end{array}$} & $8^{*}$ & $1.5-0^{* *}$ & $2.6-0^{* *}$ \\
\hline & 16 & $1.5-0^{* *}$ & $2.6-0^{* *}$ \\
\hline & 32 & $1.5-52.5$ & $2.6-52.5$ \\
\hline & $32.5^{* * *}$ & $1.5-1.5$ & - \\
\hline & $34^{* * *}$ & - & $1.5-1.5$ \\
\hline & 64 & $1.5-11.8$ & $2.6-11.8$ \\
\hline \multirow{9}{*}{$\begin{array}{l}\text { Lowland/ } \\
\text { Night-time }\end{array}$} & $8^{*}$ & $0-0^{* *}$ & $0-0^{* *}$ \\
\hline & 16 & $0-0^{* *}$ & $0-0^{* *}$ \\
\hline & 32 & $0-0^{* *}$ & $0-0^{* *}$ \\
\hline & $38.5^{* * *}$ & $0-1.5$ & - \\
\hline & $40.5^{* * *}$ & - & $0-1.5$ \\
\hline & 64 & $0-9.3$ & $0-9.3$ \\
\hline & 16 & $0-285$ & $0-285$ \\
\hline & 32 & $0-45.2$ & $0-45.2$ \\
\hline & 64 & $0-34.8$ & $0-34.9$ \\
\hline
\end{tabular}

Note:

*) existing in average distance.

**) problem in the distance.

***) minimum distance for lowland with maximum wind speed on noise based on WHO Standard and minimum wind speed for restoring thermal comfort.

Source: Author's illustration, July 2017.

\section{Horizontal and vertical air movement and sound propagation}

Analysis of horizontal and vertical air movement from source (outdoor and ground floor to $2^{\text {nd }}$ and $3^{\text {rd }}$ floor) has been conducted not only to get relationships between source and receiver but also as determining tools for existing building improvement. Figure 8 shows that most of the indoor measurement result is lower than source wind speed in horizontal air movement, reveal the conventional ventilation is not relevant to the current condition. Thus, vertical ventilation could be the logical option. In addition, by providing total vertical ventilation and limiting horizontal ventilation, the building in the tropical urban environment could be resilient in any situation of surrounding environment.

Simulation for ventilation resulted by CFD in Figure 9 illustrated that both horizontal (cross ventilation) and vertical ventilation have capability and potency in physiological cooling. As mentioned above, this condition for the ideal condition of opened and 


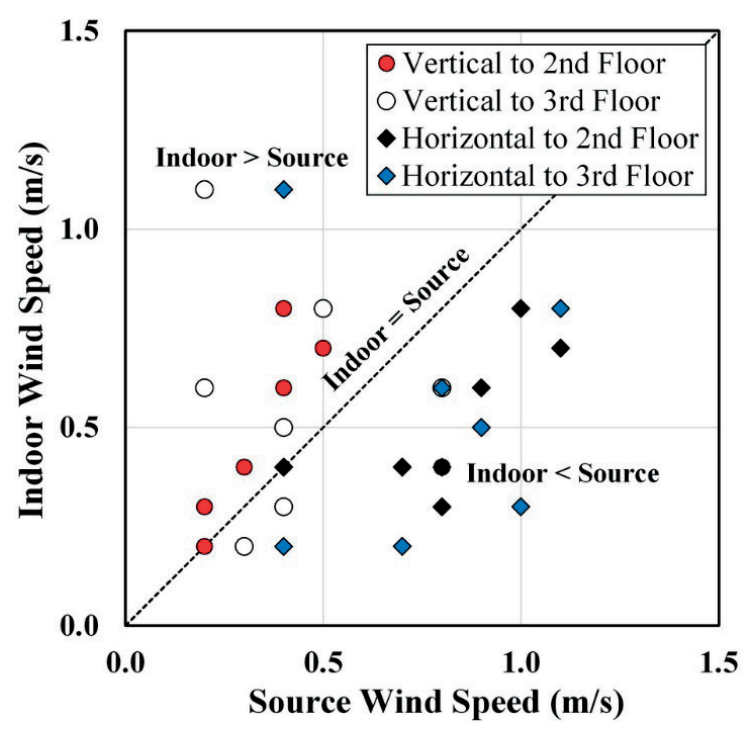

Fig. 8. Horizontal and vertical air movement Source: Author's field measurement and illustration, July 2017.

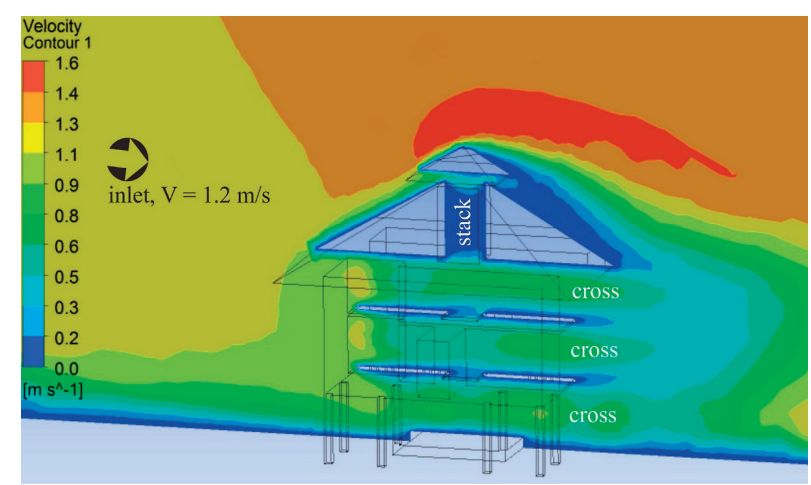

Fig. 9. Horizontal and vertical ventilation Source: Author's simulation and illustration, July 2017. high permeability of urban density that it could result in $1.2 \mathrm{~m} / \mathrm{s}$ of inlet wind speed. Vertical ventilation indicated by building's stack as architecture technology has been prepared for the future denser environment. Therefore, in the current time, it is not as effective as horizontal (cross) ventilation. By this anticipated design, the resilient concept enhances the performance of this tropical urban model. However, it should be directed to flexible and operable present time condition and the environmental change. To accelerate better wind for physiological cooling, the tropical building model is suggested to have elevated design. In line with Liu et al. (2016), for improving the thermal comfort for the limited adjacent area, the lower open space provides much better thermal comfort.

Different from air movement, sound propagation is mostly affected by distance as shown in Figure 10. The noise source from traffic has a greater contribution to the global, it effects on road noise by vehicle. However, in the case of community noise as the main source for the urban environment because potential sound attenuation could be all directions, horizontal and vertical when the traffic tends to horizontal way only. In addition to Wang et al. (2015), on the perceived noise loudness and annoyance, the influences of a community (human-related factors) are more considerably related to the housing-related factors. Although the horizontal propagation tends to be a higher problem than the vertical, outdoor activities are still as the main source compared to indoor activities. Furthermore, by analyzing this pattern, the existing has a potency to be developed better in the future.

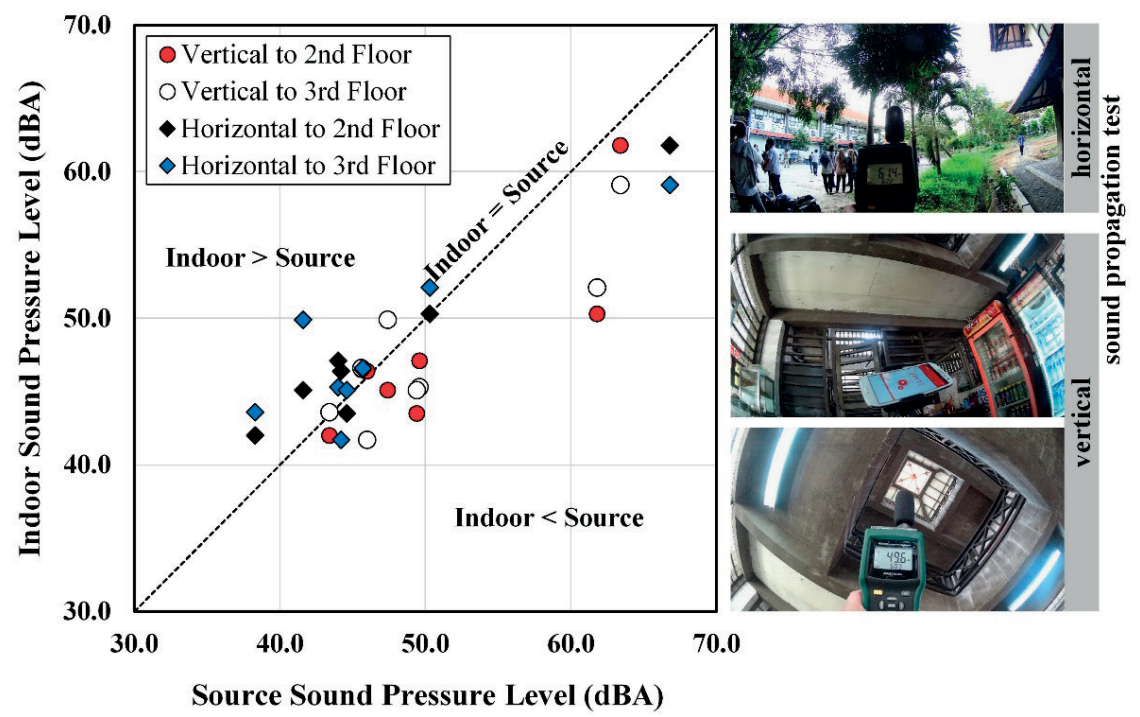

Fig. 10. Horizontal and vertical noise propagation Source: Author's field measurement, photograph, and illustration, May-July 2017. 

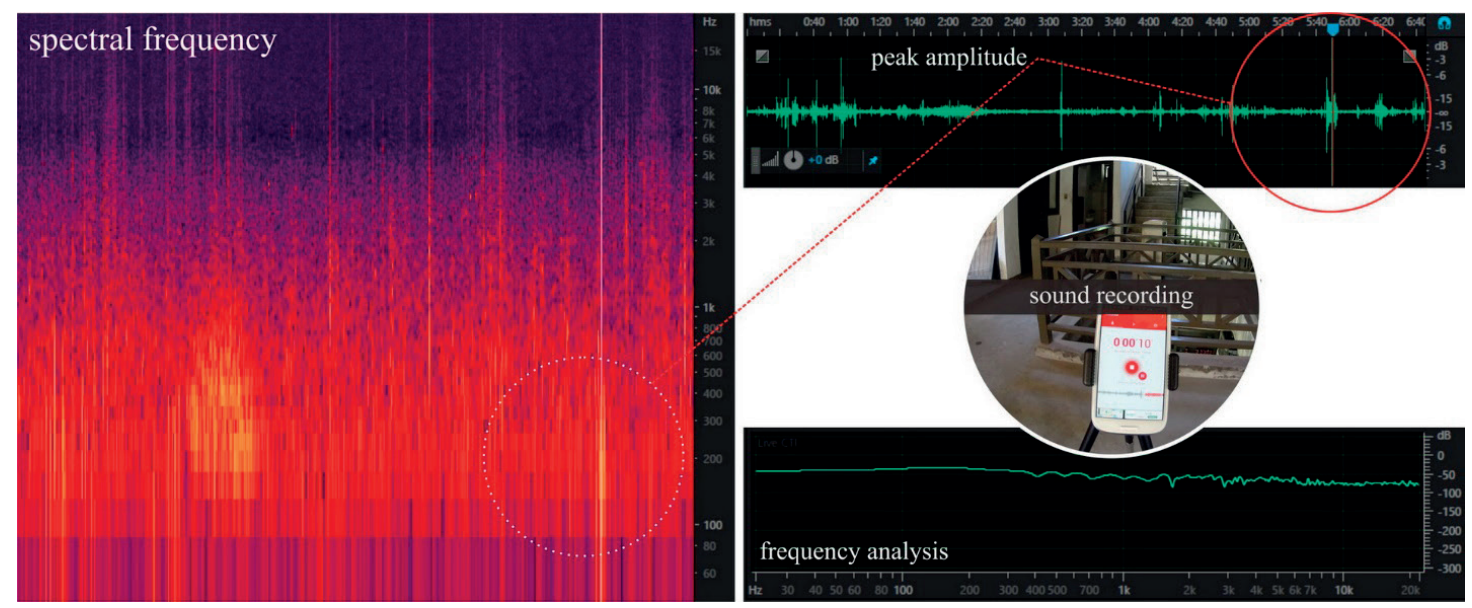

Fig. 11. Sound analysis for $2^{\text {nd }}$ floor in peak of noise in daytime of weekday Source: Author's field measurement and illustration, May-July 2017.

This research evaluates the probability of vertical building (housing) which is potentially adopted for urban people in the current time and the future. Figure 11 confirms that sound recording for the indoor environment in upper floor is highly affected by the low frequency of noise. It means that providing material as barrier vertically and horizontally will be better for having high absorption coefficient for longwave sound. It is not recommended for high reflection coefficient material because it could make a flanking effect for vertical propagation if the barrier is designed in a horizontal way. Traditionally, tropical building using timber are confirmed for acoustic and thermal insulation as Caniato et al. (2017) suggested and it shows how scientific analysis may help to deal with new buildings style. It should be realized that with high acoustic insulation, comfort, and high energy performance, the tropical building material usually has a role as building fire hazard. As part of urban design elements, the appearance of suggested material and barrier should refer to the local regulation related to other aspects such eco-friendly and sustainable issues. Related to the findings of Hodgson, Khaleghia (2012), the indoor environments in buildings depends on the degree of design compliance and its implementation with standards and design guidelines. Therefore, this study refers to the thermal and acoustical standard as explained in the previous section.

\section{Recommendation for thermoacoustic improvement}

Different from the material analysis, the ventilation for thermal and noise has opposite rule. The requirement is determined by the percentage of Window to Wall Ratio (WWR), Area of Aperture compared to
Area of Wall in accelerating air movement (airflow) for ventilation requirement and reducing environmental noise. WWR could be the one of building design element which effects on resilient and sustainable design strategies conflict (Phillips et al. 2017). Meanwhile, as the window part of a building's envelope and a prominent architectural feature of the building, WWR and its allowed maximum in terms of thermal autonomy are the signature and reflection of local ambient temperature amplitude and the variety of envelopes of building in each locality (Ma et al. 2015).

For minimum for thermal improvement, Q (air flow rate) is $0.024 \mathrm{~m}^{3} / \mathrm{s}$; For higher air flow rate, larger aperture area needed in constant of sufficient wind speed for physiological cooling. Conducted in previous research (Mahn, Pearse 2012; Janusevicius et al. 2016; Yu et al. 2017), the noise control is calculated through analysis of Area of the aperture from Sound Reduction Index (SRI) of building material and opened aperture (developed from De Salis et al. (2002), see Equation (4)). The setting for WWR analysis considers distance important factor on noise propagation, different distance source to receiver effects on the maximum of WWR. The distance is not significant for air movement of the thermal environment.

$$
\begin{aligned}
& \text { SRIW }+\mathrm{A}= \\
& -10 \log \left[\frac{\mathrm{AW} \cdot 10^{\left(\frac{-\mathrm{SRIW}}{10}\right)}+\mathrm{AA} \cdot 10^{\left(\frac{-\mathrm{SRIA}}{10}\right)}}{(\mathrm{AW}+\mathrm{AA})}\right],
\end{aligned}
$$

where: SRI $\mathrm{W}_{\mathrm{W}}$ - Sound Reduction Index of a composite panel $[\mathrm{dB}] ; \mathrm{A}_{\mathrm{W}}-$ Wall Area $\left[\mathrm{m}^{2}\right]$; $\mathrm{SRI}_{\mathrm{W}}-$ Sound Reduction Index of Wall (opened aperture, 
$\left.\mathrm{SRI}_{\mathrm{W}}=0\right)[\mathrm{dB}] ; \mathrm{A}_{\mathrm{A}}-$ Aperture Area $\left[\mathrm{m}^{2}\right] ; \mathrm{SRI}_{\mathrm{A}}-$ Sound Reduction Index of Aperture [dB].

Table 2 shows how the various distance results in different criteria for integrating thermal comfort with noise propagation. Because of higher temperature than night-time, the ventilation for physiological cooling is only required for daytime only, minimum WWR is $0.13 \%$ for lowland. There is a requirement of which condition of WWR should be $0 \%$ (no aperture or totally closed requirement by minimum distance). It is rarely happening in real condition because the distance is very close (not more than $1 \mathrm{~m}$ ).

The method for improving the thermoacoustic environment is analyzing WWR in accelerating air movement and controlling noise propagation into a building. WHO noise limit results range from WWR 0.13-5.24\% for lowland daytime, $0-3.24 \%$ for lowland night-time, see Figure 12. Meanwhile, the critical distances for closing the aperture (WWR $=0 \%$ for noise control) are $3.95 \mathrm{~m}$ and 4.65 for lowland daytime and lowland night-time, respectively. Moreover, the safe distances to use aperture for all area of wall (WWR $=100 \%$ for noise control) are $22.1 \mathrm{~m}$ and $25.9 \mathrm{~m}$, for lowland daytime and lowland night-time, respectively. Although it is difficult providing that distance, considering WWR and building material in low frequency could be important sustainable factors in resolving both thermal and acoustical problem.

The results consider the conceptual design of tropical urban model on the combined design of thermal and acoustics issues stated in the objective of this study. While Kang et al. (2013) explained the highest frequency of thermal comfort that was obtained for

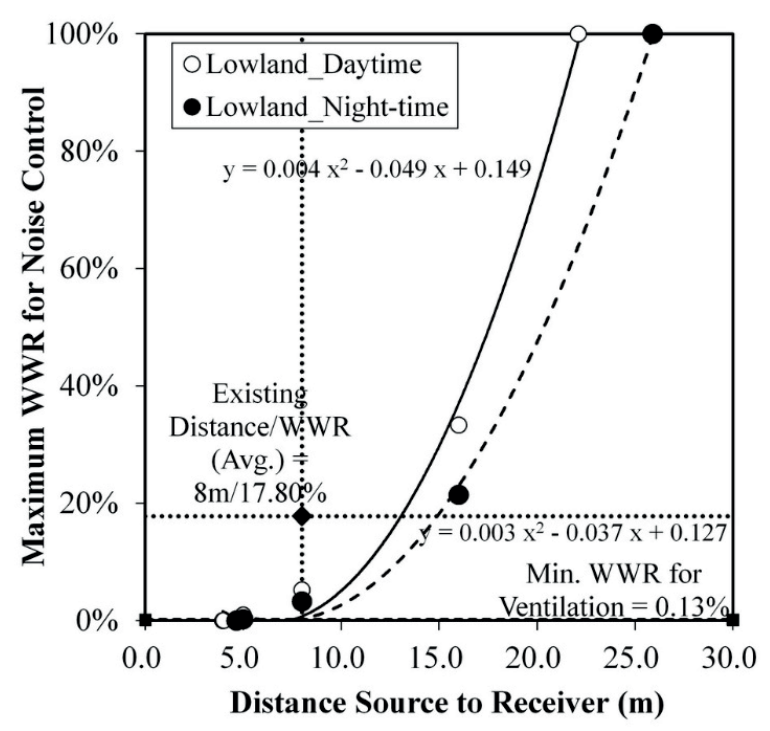

Fig. 12. WWR recommendation

Source: Author's illustration, July 2017.
Table 2. Summary for WWR for ventilation, restoring thermal comfort and controlling noise for various distance samples.

\begin{tabular}{|c|c|c|c|}
\hline \multirow[b]{2}{*}{$\begin{array}{l}\text { Location/ } \\
\text { Time }\end{array}$} & \multirow[b]{2}{*}{$\begin{array}{c}\text { Distance } \\
\text { Samples } \\
\text { (m) }\end{array}$} & \multicolumn{2}{|c|}{ WWR Requirement } \\
\hline & & $\begin{array}{l}\text { Minimum } \\
\text { for Thermal } \\
\text { Improvement }\end{array}$ & $\begin{array}{l}\text { Maximum } \\
\text { for Noise } \\
\text { Improvement }\end{array}$ \\
\hline \multirow{5}{*}{$\begin{array}{l}\text { Lowland/ } \\
\text { Daytime }\end{array}$} & $8^{*}$ & $0.13 \%$ & $5.24 \%$ \\
\hline & 0.72 & - & - \\
\hline & 4.02 & - & - \\
\hline & 3.95 & $0.13 \%$ & $0 \% * *$ \\
\hline & 22.1 & $0.13 \%$ & $100 \% * * *$ \\
\hline \multirow{9}{*}{$\begin{array}{l}\text { Lowland/ } \\
\text { Night-time }\end{array}$} & $8^{*}$ & $0 \% * * * *$ & $3.24 \%$ \\
\hline & 0.75 & - & - \\
\hline & 4.21 & - & - \\
\hline & 4.65 & $0 \%$ & $0 \% * *$ \\
\hline & 25.9 & $0 \%$ & $100 \% * * *$ \\
\hline & 0.29 & - & - \\
\hline & 1.63 & - & - \\
\hline & 0.91 & $0 \%$ & $0 \% * *$ \\
\hline & 5.15 & $0 \%$ & $100 \% * * *$ \\
\hline
\end{tabular}

Note:

*) existing in average distance.

**) no aperture (totally closed) requirement by minimum distance.

***) totally opened aperture requirement by minimum distance.

****) no need aperture for night-time.

Source: Author's illustration, July 2017.

specific wind speed, this study recommends the ventilation strategy represented by WWR. Designing the thermal control could not ignore the acoustical factor. Therefore, the WWR is one of key point for the tropical case. It could also be the answer to the challenge for resilient and sustainable design strategies conflict (Phillips et al. 2017).

\section{Conclusions}

Adaptation of thermoacoustic environment has been analyzed by providing a tropical urban model as a case object. Through field experiment and mathematical calculation referring to the standard, this research points out a conceptual design of tropical urban model on integrated design of thermal and acoustics issues which consist of thermal performance and urban community noise control. In line with the previous finding (Samodra 2016), the results recommend that the noise barrier of the building should consider 5.24\% of the maximum window to wall ratio (WWR) horizontally and vertically. In addition, vertical ventilation is the best solution for urban density, but the orientation 
and its flanking noise effect to the passive cooling. Furthermore, wind acceleration, source to receiver distance, and building material are some factors which have a high contribution in addition to WWR. As the response to the challenge for resilient and sustainable design strategies conflict offered by Phillips et al. (2017), the research findings could be determined as a suggestion for development of technology in architecture design and in small scale, it also has a contribution to the urban design recommendation and guideline. For future works, the material evaluation to deal thermal and noise control could be a novel idea and building material industry should consider how to produce thermoacoustic material properties for urban resilience.

\section{Funding}

This work was supported by the under Grant Penelitian Doktor Baru No. 881/PKS/ITS/2017 by Dana Non PNBP ITS 2017. The authors gratefully acknowledge this financial and technical supports.

\section{References}

Anderies, J. M. 2014. Embedding built environments in socialecological systems: resilience-based design principles, Building Research and Information 42(2): 130-142. https://doi.org/10.1080/09613218.2013.857455

ANSI/ASHRAE Standard 62.1-2004. Ventilation for Acceptable Indoor Air Quality.

Aynsley, R. M.; Spruill, M. 1990. Thermal comfort models for outdoor thermal comfort in warm humid climates and probabilities of low wind speeds, Journal of Wind Engineering and Industrial Aerodynamics 36: 481-488. https://doi.org/10.1016/0167-6105(90)90331-6

Berglund, B.; Lindvall, T.; Schwela, D.; Goh, K. T. 2000. Guidelines for community noise. World Health Organization (WHO), Geneva.

Caniato, M.; Bettarello, F.; Schmid C.; Fausti, P. 2016. Assessment criterion for indoor noise disturbance in the presence of low frequency sources, Applied Acoustics 113: 22-33. https://doi.org/10.1016/j.apacoust.2016.06.001

Caniato, M.; Bettarello, F.; Ferluga, A.; Marsich, L.; Schmid, C.; Fausti, P. 2017. Thermal and acoustic performance expectations on timber buildings, Building Acoustics 24(4): 219-237. https://doi.org/10.1177/1351010X17740477

Coley, D.; Herrera, M.; Fosas, D.; Liu, C.; Vellei 2017. Probabilistic adaptive thermal comfort for resilient design, Building and Environment 123: 109-118. https://doi.org/10.1016/j.buildenv.2017.06.050

De Salis, M. H. F.; Oldham, DJ.; Sharples, S. 2002. Noise control strategies for naturally ventilated buildings, Building and Environment 37: 471-484. https://doi.org/10.1016/S0360-1323(01)00047-6

Freihoefer, K.; Guerin, D.; Martin, C.; Kim, H-Y.; Brigham, J. K. 2015. Occupants' satisfaction with, and physical readings of, thermal, acoustic, and lighting conditions of sustainable office workspaces, Indoor and Built Environment 24: 457-472. https://doi.org/10.1177/1420326X13514595
Hodgson, M.; Alireza Khaleghi, A. 2012. Factors affecting ventilation and acoustical quality in a sustainably-designed and in conventional buildings - a pilot study, Building Acoustics 19: 313-325. https://doi.org/10.1260/1351-010X.19.4.313

Huang, L.; Zhu, Y.; Ouyang, Q.; Cao, B. 2012. A study on the effects of thermal, luminous, and acoustic environments on indoor environmental comfort in offices, Building and Environment 49: 304-309.

https://doi.org/10.1016/j.buildenv.2011.07.022

Indonesian National Standard (SNI) No. 03-6390-2011. Energy Conservation for Air Conditioning System in Building.

Janusevicius, T.; Mazuolis, J.; Butkus, D. 2016. Sound reduction in samples of environmentally friendly building materials and their compositions, Applied Acoustics 113: 132-136. https://doi.org/10.1016/j.apacoust.2016.06.014

Kang, K-N.; Song, D.; Schiavon, S. 2013. Correlations in thermal comfort and natural wind, Journal of Thermal Biology 38: 419-426. https://doi.org/10.1016/j.jtherbio.2013.06.001

Kodama, Y.; Funo S.; Takemasa, K.; Hokoi, S.; Yamamoto, N.; Uno, T. 1999. Surabaya eco-house an experiment on passive design in a tropical climate, part 2: evaluation and simulation of the effects on thermal performance, in PLEA'99 Conference, 22-24 September 1999, Brisbane, Australia.

Kruger, E. L.; Zannin, P. H. T. 2007. Acoustic and thermal field investigation of low-cost dwellings, a case study in Brazil, Applied Acoustics 68: 1213-1223.

https://doi.org/10.1016/j.apacoust.2006.07.001

Laboy, M.; Fannon, D. 2016. Resilience theory and praxis: a critical framework for architecture, Enquiry 13(1): 39-53.

Liu, J.; Niu, J.; Qian Xia, Q. 2016. Combining measured thermal parameters and simulated wind velocity to predict outdoor thermal comfort, Building and Environment 105: 185-197. https://doi.org/10.1016/j.buildenv.2016.05.038

Ma, P.; Wang, L. S.; Guo, N. 2015. Maximum window-to-wall ratio of a thermally autonomous building as a function of envelope U-value and ambient temperature amplitude, Applied Energy 146: 84-91.

https://doi.org/10.1016/j.apenergy.2015.01.103

Mahn, J.; Pearse J. 2012. The Uncertainty of the proposed single number ratings for airborne sound insulation, Building Acoustics 19(3): 145-172. https://doi.org/10.1260/1351-010X.19.3.145

Minister for The Environment Decree, Republic of Indonesia, No. 48/MENLH/11/1996. Noise Level Standard.

Paris-Newton, J. A. E.; Prokofieva, E.; Henry, N. 2016. Improvement of thermal insulation of residential buildings' façades via acoustic insulation, Building Acoustics 23(2): 120-128. https://doi.org/10.1177/1351010X16648562

Phillips, R.; Troup, L.; Fannon, D.; Eckelman, M. J. 2017. Do resilient and sustainable design strategies conflict in commercial buildings? A critical analysis of existing resilient building frameworks and their sustainability implications, Energy and Buildings 146: 295-311. https://doi.org/10.1016/j.enbuild.2017.04.009

Roaf, S.; Fuentes, M.; Thomas, S. 2007. Ecohouse. Oxford: Architectural Press.

Sakamoto, S. 2015. Road traffic noise prediction model "ASJ RTN-Model 2013": Report of the research committee on road traffic noise, Acoustical Science and Technology 36(2): 49-108. https://doi.org/10.1250/ast.36.49

Samodra, F. X. T. B. S. 2016. Proposal for thermal and noise environment improvement of the traditional house in Indonesia: $\mathrm{PhD}$ Thesis. Pusan National University, Busan, Korea. 
Tanaka, S.; Shiraishi, B. 2008. Wind effects on noise propagation for complicated geographical and road configurations, Applied Acoustics 69: 1038-1043. https://doi.org/10.1016/j.apacoust.2007.07.007

Vellei, M.; Herrera, M.; Fosas, D.; Natarajan, S. 2017. The influence of relative humidity on adaptive thermal comfort, Building and Environment 124: 171-185. https://doi.org/10.1016/j.buildenv.2017.08.005

WHO. 1990. WHO/EHE/RUD/90.2 (1990): Indoor Environment: Health Aspect Air Quality, Thermal Environment, Light and Noise. World Health Organization.

Yu, X.; Lau, S. K.; Cheng, L.; Cui, F. 2017. A numerical investigation on the sound insulation of ventilation windows, Applied Acoustics 117: 113-121. https://doi.org/10.1016/j.apacoust.2016.11.006

Wang, C.; Si, Y.; Abdul-Rahman, H.; Wood, L. C. 2015. Noise annoyance and loudness: Acoustic performance of resi- dential buildings in tropics, Building Services Engineering Research and Technology 36(6): 680-700.

https://doi.org/10.1177/0143624415580444

Zonouz, H. K. 2015. Effects of climate conditions in formation and development of Zonuz's historical garden city architecture, Journal of Architecture and Urbanism 39(2): 124-131. https://doi.org/10.3846/20297955.2015.1048839

\section{FX TEDDY BADAI SAMODRA}

Earned PhD Architecture Degrees from Pusan National University, Busan, Korea. He is a Lecturer in Department of Architecture, Institut Teknologi Sepuluh Nopember, Surabaya, Indonesia. Research interests: Building Thermal and Environmental Acoustics, Tropical and Green Architecture, and Building Services. 